\title{
Análise dos desafios do consumismo e do desenvolvimento sustentável no Brasil
}

\author{
Analysis of the challenges of consumerism and sustainable development in Brazil \\ Análisis de los desafíos del consumismo y el desarrollo sostenible en Brasil
}

Recebido: 14/01/2022 | Revisado: 18/01/2022 | Aceito: 26/01/2022 | Publicado: 27/01/2022

Rosana Santos de Almeida

ORCID: https://orcid.org/0000-0001-8097-1074 Universidade Federal de Campina Grande, Brasil

E-mail: rosana.santos@estudante.ufcg.edu.br

Agílio Tomaz Marques

ORCID: https://orcid.org/0000-0001-8364-5063 Universidade Federal de Campina Grande, Brasil

E-mail: agiliotomaz@hotmail.com

Raquel Formiga de Medeiros ${ }^{1}$

ORCID: https://orcid.org/0000-0002-1198-5015

Universidad del Museo Social Argentino, Argentina E-mail: raquelfdm@hotmail.com

Hugo Sarmento Gadelha ${ }^{2}$

ORCID: https://orcid.org/0000-0001-9414-0554 Universidad del Museo Social Argentino, Argentina E-mail: hugoscurso@uol.com.br

Hiran Mendes Castro Filho ${ }^{3}$

ORCID: https://orcid.org/0000-0002-1418-159X Universidad del Museo Social Argentino, Argentina E-mail: hirancastro@gmail.com

Suzana Araújo dos Santos ORCID: https://orcid.org/0000-0001-5955-9421 Universidade Federal de Campina Grande, Brasil E-mail: suzana.santos2007@yahoo.com.br Adryele Gomes Maia ORCID: https://orcid.org/0000-0002-7433-7138 Universidade Federal do Rio Grande do Norte, Brasi E-mail: adryelegm@gmail.com

Francisco Igor Dalles da Mata Vieira ORCID: https://orcid.org/0000-0002-9219-9090 Instituto Federal do Ceará, Brasil E-mail: igordm@gmail.com

\begin{abstract}
Resumo
O presente artigo se dispõe a reavivar a discussão do problema do consumo sustentável. A degradação ambiental, tem se apresentado como um dos problemas de ordem social, que se dá principalmente em decorrência da produção desenfreada e do consumismo exacerbado, e esses são alguns dos problemas latentes e amplamente discutidos na atualidade. Em face dessa problemática da utilização dos princípios do desenvolvimento sustentável, busca-se minimizar através dessa pesquisa, estes estigmas que afetam sensivelmente a sociedade. Nesse sentido, esse trabalho objetiva abordar a essas discussões, sob o viés do modelo e dos conceitos de desenvolvimento sustentável, por meio da educação ambiental, consumo e produção responsável, entre outros. Para tanto, realizou-se para a construção da pesquisa o método de abordagem dedutivo, a partir da pesquisa bibliográfica de natureza qualitativa através da leitura de textos, teses, dissertações, revistas e livros, com posterior analise da parte documental que foi realizada através do estudo de leis constitucionais e infraconstitucionais. A partir da pesquisa como resultado, observou-se que apesar de várias medidas terão sido tomadas em função da promoção do desenvolvimento sustentável frente ao consumismo, ainda há muito que se desmitificar e fazer, antigos e equivocados conceitos devem ser revistos e novas posturas frente aos problemas socioambientais devem ser tomadas e encorajadas. Em síntese, o consumo sustentável se apresenta como uma das possibilidades de tratamento da questão dos impactos gerados pelo consumismo ele envolve mudanças de atitude aliadas à necessidade de transformação do sistema de valores e atitudes dos cidadãos na esfera pública.
\end{abstract}

Palavras-chave: Desenvolvimento Sustentável; Meio Ambiente; Consumismo.

\footnotetext{
${ }^{1}$ Doutoranda pela Universidad del Museo Social Argentino.

${ }^{2}$ Doutorando pela Universidad del Museo Social Argentino.

${ }^{3}$ Doutorando pela Universidad del Museo Social Argentino.
} 


\begin{abstract}
This article aims to revive the discussion of the problem of sustainable consumption. Environmental degradation has been presented as one of the social problems, which occurs mainly as a result of unbridled production and exacerbated Consumerism, and these are some of the latent and widely discussed problems today. In the face of this problem, the use of the principles of sustainable development, seeks to minimize through this research these stigmas that significantly affect society. In this sense, this work aims to address these discussions, under the bias of the model and concepts of sustainable development, through environmental education, responsible consumption and production, among others. In order to do so, the deductive method of approach was carried out for the construction of the research, from the bibliographic research of a qualitative nature through the analysis of texts, theses, dissertations, magazines and books, with subsequent analysis of the documentary part through analysis content of constitutional and infra-constitutional laws. From the research as a result, it was observed that although several measures will have been taken in order to promote sustainable development in the face of consumerism, there is still a lot to demystify and do, old and mistaken concepts must be reviewed and new attitudes towards the socioenvironmental problems must be taken up and encouraged. In summary, sustainable consumption is presented as one of the possibilities for dealing with the issue of impacts generated by consumerism, it involves changes in attitude allied to the need to transform the system of values and attitudes of citizens in the public sphere.
\end{abstract}

Keywords: Sustainable Development; Environment; Consumerism.

\title{
Resumen
}

Este artículo tiene como objetivo revivir la discusión sobre el problema del consumo sostenible. La degradación ambiental ha sido presentada como uno de los problemas sociales, que se da principalmente como consecuencia de la producción desenfrenada y del consumismo exacerbado, y estos son algunos de los problemas latentes y ampliamente discutidos en la actualidad. Ante esta problemática, el uso de los principios del desarrollo sostenible, busca minimizar a través de esta investigación estos estigmas que afectan significativamente a la sociedad. En ese sentido, este trabajo tiene como objetivo abordar estas discusiones, bajo el sesgo del modelo y los conceptos de desarrollo sostenible, a través de la educación ambiental, el consumo y la producción responsable, entre otros. Para ello se realizó el método de enfoque deductivo para la construcción de la investigación, desde la investigación bibliográfica de carácter cualitativo pasando por el análisis de textos, tesis, disertaciones, revistas y libros, con el posterior análisis de la parte documental. a través del análisis de contenido de las leyes constitucionales e infraconstitucionales. De la investigación como resultado se observó que si bien se habrán tomado varias medidas con el fin de promover el desarrollo sostenible frente al consumismo, aún queda mucho por desmitificar y hacer, se deben revisar viejos y erróneos conceptos y nuevas actitudes. hacia los problemas socioambientales deben ser asumidos y fomentados. En síntesis, el consumo sustentable se presenta como una de las posibilidades para enfrentar el tema de los impactos generados por el consumismo, implica cambios de actitud aliados a la necesidad de transformar el sistema de valores y actitudes de los ciudadanos en la esfera pública.

Palabras clave: Desarrollo Sostenible; Medio Ambiente; Consumismo.

\section{Introdução}

O consumo exagerado é facilmente identificado como um dos maiores desafios ao para que seja alcançado os fins propostos pelo princípio do desenvolvimento sustentável. Sendo que essa constatação foi o que estimulou os participantes da Conferência do Rio em 1992, a introduzirem, na Declaração do Rio sobre Meio Ambiente e Desenvolvimento, um princípio que relaciona o desenvolvimento sustentável a necessidade de redução dos níveis atuais de consumo (Oliveira, 2012).

Nessa esteira, o consumismo tem se tornado uma das características mais marcantes da sociedade capitalista que são operados pelo desenvolvimento do modo de produção capitalista que trouxe uma infinidade de mudança de valores e de ideologia onde a sociedade de consumo tem a visão de mundo que remete a um comprometimento do individual com a lógica de acumulação, onde a sociedade explora os recursos naturais, degradando e extinguindo (Guimarães, 2002).

Desse modo, o desenvolvimento sustentável surge com o papel de conciliador entre o desenvolvimento socioeconômico e a utilização dos recursos naturais de forma racional, para que as futuras gerações não sejam prejudicadas. E mesmo sendo um projeto muito debatido, ele ainda não é aplicado de maneira consistente. 
Outrossim, o modelo atual de crescimento econômico que tem gerado muita fartura, longevidade, conforto e muitas opções para o consumo de uma pequena parcela da sociedade, por outro lado, tem promovido uma intensa degradação ambiental.

Assim, o principal objetivo deste trabalho é indagar se é possível uma sociedade consumista alcançar o desenvolvimento sustentável e até que ponto este desenvolvimento é viável? Para tanto, é preciso que seja discutido sobre a importância do desenvolvimento sustentável aliado ao consumo consciente.

Para a construção dessa pesquisa foi utilizado o método de abordagem dedutivo, através da análise dos desafios do consumismo e do desenvolvimento sustentável no Brasil. a partir da pesquisa bibliográfica de natureza qualitativa através da leitura de textos, teses, dissertações, revistas e livros, com posterior análise dos da parte documental por meio de análise de conteúdo de leis constitucionais e infraconstitucionais.

Para melhor compreensão essa pesquisa se divide em três capítulos, no capitulo primeiro é tratado sobre o tema do desenvolvimento sustentável no Brasil, o segundo capitulo traz uma abordagem sobre como se deu os dilemas do consumismo no Brasil, e por fim o terceiro capítulo aborda sobre os desafios do consumismo sustentável na atualidade.

\section{Desenvolvimento Sustentável no Brasil}

É notório que devido as mudanças ocorridas por meio do liberalismo e neoliberalismo econômico, que vem se evidenciando nos últimos tempos, tendo como consequência a provocação de uma relação cada vez mais predatória do homem com a natureza. Nesse sentido esses modelos econômicos levam a sociedade a um desastre ambiental que tem dimensões incalculáveis (Lowi, 2005).

Isso, ocorre principalmente porque tem como uma das consequências uma ruptura dos valores e crenças que sustentam a sociedade e a economia mundial que vem acontecendo desde a segunda metade do século XX e se perpetua até os dias atuais, as quais tem demostrado uma velocidade dessas mudanças tem se tornado a principal característica do mundo contemporâneo, e dessa forma tem sinalizado a incapacidade do homem em compreender a realidade em sua totalidade (Teixeira, 2005).

Foi a partir da década de 1970, que surgiu o conceito de desenvolvimento e essa vinha incorporado a uma preocupação mundial ambiental. Tendo acontecido como marco inicial a realização da Conferência das Nações Unidas sobre o Meio Ambiente Humano em Estocolmo (Suécia) em 1972.

Nessa conferencia, vários representantes de diversos países discutiam a problemática ambiental e sua proporção e sua dimensão global, também foram definidos pelos 113 países que estavam participando do evento, as diretrizes da política ambiental da ONU para os 20 anos subsequentes e, diante de tal proposta, foi criado o Programa das Nações Unidas para o Meio ambiente (PNUMA). Esse programa tinha como objetivos principais o objetivo de incentivar às nações a desenvolver uma legislação ambiental. Nesta senda, foi criado também o Fundo Voluntário para o Meio Ambiente que seria gerido pelo PNUMA (Martins, 2006).

Essa ideia de desenvolvimento sustentável, urge na ideia do Ecodesenvolvimento de Sachs e Strong que teve sua consolidação no Relatório da Comissão Mundial sobre o Meio Ambiente e Desenvolvimento da ONU de 1987 conhecido como "Our Common Future" ou "Relatório Brundtland" e estava centrado em três eixos principais: crescimento econômico, equidade social e equilíbrio ecológico (CPDS, 2000).

Outro grande evento em prol do desenvolvimento sustentável aconteceu no Brasil na década de 1990, quando sediou a Conferência das Nações Unidas sobre o Meio Ambiente e Desenvolvimento (Eco-92), no Rio de Janeiro, que trouxe o teve o objetivo de trazer de volta ao foco a agenda política internacional. Dessa forma tratava-se, então, de avançar um conceito de 
desenvolvimento sustentável mais amplo, trazendo a unificação da preservação ambiental e do uso racional dos recursos naturais com o imperativo da resolução dos problemas sociais.

Surge dessa Conferência, apesar dos conflitos de interesses dos presentes, a elaboração de um programa de ação de longo prazo e amplo impacto internacional, a Agenda 21, no qual lançaram-se algumas bases para se praticar, em termos globais, o emergente conceito de desenvolvimento sustentável.

Diante disso, a construção da Agenda 21 do Brasil, surgiu de um processo de planejamento participativo com o intuito de analisar a situação atual do país para que fossem identificadas as potencialidades e fragilidades e, dessa forma, vislumbrar o desenvolvimento futuro de forma sustentável.

E para isso, a Agenda 21 foi elaborada de acordo com a realidade brasileira de forma multissetorial, feita a partir de diagnósticos setoriais que foram produzidos por especialistas, apoiados por participação de representantes de diferentes setores da sociedade de todas as regiões do país, com apoios de participantes da área acadêmica (CPDS, 2000).

Nessa perspectiva, no ano de 1996, foram publicadas pela Comissão para o Desenvolvimento Sustentável das Nações Unidas, algumas metodologias que serviam como vários indicadores. Ademais, nos anos de 2002 e 2004, foram lançados os primeiros indicadores brasileiros de desenvolvimento sustentável que foram produzidos pelo Instituto Brasileiro de Geografia e Estatística (IBGE).

No que diz respeito as publicações que foram produzidas, essas compreendem sempre diversos indicadores que foram utilizados para os diferentes aspectos observados. No entanto, algumas ferramentas foram desenvolvidas, e compilam os indicadores para avaliar o desenvolvimento sustentável, e dentre elas três tem se destacado são elas: O Método da "Pegada Ecológica”, o Barômetro de Sustentabilidade e o Painel de Sustentabilidade.

Percebe-se que ao longo dos anos, vários métodos foram criados para servir de indicadores do desenvolvimento sustentável, porém esses métodos são diversos e ainda não se chegou a um único indicador devendo o governo e sociedade ter moderação no consumo racional de produtos para que o meio ambiente seja preservado.

\section{Dilemas do Consumismo no Brasil}

Um dos primeiros passos para se alcançar a sustentabilidade no Brasil, seria o consumo consciente, onde o consumidor, no plano individual, pode adotar atitudes conscientes, através da mudança sua postura no tocante ao consumo de forma a contribuir para minimizar os impactos que são gerados pelo descarte inadequado desses produtos no meio ambiente.

O consumo consciente não é necessariamente sustentável, embora todo consumo sustentável seja consciente. A questão da sustentabilidade é uma oitava maior do consumo consciente, isso significa dizer que os cidadãos para podem diminuir seu consumo sob a prerrogativa de estar contribuindo para minimizar os impactos ao meio ambiente, já o consumo sustentável diz respeito a toda uma cadeia que é desenvolvida na produção do produto de forma sustentável (Feldmann \& Crespo, 2003).

Aliado a isso, o consumo consciente poderia minimizar o excesso de consumo, a medida em que legitimaria quantidade racionalizada de consumo, realizada de forma consciente. Ajudando assim o indivíduo sentir-se-ia isento das responsabilidades ambientais e sociais porque, em seu consumo, ele adotou o uso consciente (Sachs, 2004).

O consumo consciente, dentre as medidas que ajudam a proporcionar o desenvolvimento sustentável, trata-se de uma medida eficaz e de pouco impacto ao meio ambiente, entretanto, é preciso que as pessoas e empresas façam uma maior divulgação na mídia para que as pessoas se conscientizem. 
Outra crítica que é feita, diz respeito ao fato de não ser tratado com maior precisão as desigualdades entre aqueles que produzem e aqueles que consomem o que foi produzido, portanto, trata-se também de um problema de acesso, que são gerados pela má distribuição da renda entre as pessoas que detém a produção e dos que fabricam os produtos (Sachs, 2004).

Essas desigualdades são provenientes da má distribuição de renda que perpetua desde os primórdios da humanidade, onde há poucas pessoas com maior poder de capital, porém os detentores da produção têm pouco poder aquisitivo para poder usufruir do produto de seu trabalho.

\section{Desafios do Consumismo Sustentável no Brasil}

Quando se fala em consumo individual, esse é muito bem visto pelo modelo capitalista de desenvolvimento econômico. De forma que, cada indivíduo tem o desejo de construir seu próprio mundo, e consumir os seus próprios produtos, ou seja, aqueles produtos que são feitos especialmente, para eles. Mas o mundo não suportaria esse consumo exagerado por parte de todos os habitantes. Porque um único planeta não suportaria o consumo de milhões de pessoas ao mesmo tempo (Cavalcante, 2011).

Diante desse intenso processo de consumismo tem se agravado, cada vez mais, a crise ambiental que enfrenta a população mundial, devido ao atual padrão de consumo e produção, que se utiliza dos recursos naturais numa velocidade bem maior e mais rápida que a natureza consegue repor Milaré (2007, p. 84).

Nesse sentido, de acordo com o Relatório Brundtland, que foi elaborado pela Comissão Mundial sobre o Meio Ambiente e Desenvolvimento, o consumo sustentável tem como objetivo principal em saber utilizar os recursos naturais para que sejam satisfeitas nossas necessidades, de forma que não seja comprometida as necessidades das próximas gerações (Cavalcante \& 2011).

Percebe-se ainda que, há um entrave na prática do consumo responsável e que há uma relação contraditória entre uma pequena parte que tem acesso aos recursos naturais e aos bens e serviços, e os que sofrem as consequências advindas dos danos ambientais causados por aqueles.

Entre os que possuem um grande poder de compra, sendo esses, uma minoria da população, por sua vez tem amplo acesso aos recursos naturais, e são os maiores responsáveis pelo consumo maçante de bens e serviços supérfluos, que para serem produzidos utilizam os recursos naturais de forma desenfreada e despreocupada com a preservação do meio ambiente (Milare,2007).

Uma das soluções que surgiram dentro do consumo sustentável vem tendo destaque o consumo verde. Que tem se caracterizado como o consumo de bens que são produzidos sob o viés de um menor impacto ambiental, tratando-se assim de um consumo consciente que é preocupado com os impactos causados por produtos e serviços.

Dessa forma, o consumo verde como é aquele em que o consumidor, dá preferência a produtos e serviços que não agridem o meio ambiente em toda sua cadeia de abastecimento, ou melhor, respeitando assim os princípios de sustentabilidade que são obrigatórios desde a obtenção da matéria prima, até na produção, distribuição, consumo e no descarte final (Pontual, 2008).

Esse consumo verde, trata-se de uma alternativa do consumo sustentável onde o consumidor tem a opção de escolha entre um produto que foi produzido dentro dos moldes tradicionais e outro produto que foi pensado de forma inovadora, porém dentro dos padrões sustentáveis desde o início da produção até seu descarte no meio ambiente. 


\section{Resultados e Discussões}

É perceptível que existe um paradigma entre a sustentabilidade ambiental e a atividade econômica, por exemplo, que não podem ser pensadas ou praticadas de forma individual ou seja, separado das questões ambiental, social, política, cultural e educacional. Dessa forma a sustentabilidade ambiental possui, um caráter integrador onde o homem e meio ambiente estão não podem ser pensados de forma individual (Almeida, 2002).

Nesse aspecto, é compreensível que para sua existência o homem precisa utilizar-se de várias formas de consumo para promover seu sustento, entretanto esse consumo deve ser feito de maneira que não venha a comprometer o meio ambiente para as gerações futuras, de modo a manter aliado o consumo ao desenvolvimento sustentável.

Em face a essa discussão é valido ressaltar que o debate em relação ao desenvolvimento sustentável atualmente está centralizado entre duas vertentes: de um lado, tem a idéia sendo gerida na esfera da economia, e desta maneira, incorpora-se a natureza, à cadeia de produção de outro, tem-se a ideia de tentar quebrar com a hegemonia do discurso econômico a expansão desmesurada da esfera econômica, indo para além da visão instrumental (Almeida, 2002).

Ou seja, existe um paradigma entre o discurso do consumismo que está ligado ao capitalismo e ao mesmo tempo do desenvolvimento sustentável aliado a essa cadeia de consumo exagerado que gera materiais descartáveis que agridem de forma direta e indireta o meio ambiente num processo que pode durar milhares de anos.

Nesse paradigma, existem alguns argumentos de que o conceito de desenvolvimento sustentável que por muitas vezes é apresentado na literatura possui consonância com a ideologia vigente do sistema capitalista. Ou seja, depreende-se, que o mesmo não atinge a "raiz" do problema, ou seja, não provoca mudanças na estrutura produtiva, nem na qualidade de vida das pessoas (Brugger, 2004).

Alguns desses argumentos são validados a medida que a teoria não é posta em prática, seja pelos consumidores, governos e empresas responsáveis por gerar produtos que não são produzidos e descartados corretamente dentro dos moldes sustentáveis pelos seus consumidores e fabricantes.

Nesse sentido, se entende que o desenvolvimento sustentável vem sendo efetivado em atividades empresariais com o intuito de se buscar a sustentabilidade do ambiente físico, não sendo contemplado assim, as outras dimensões como cultura, educação e política, que constituem sua razão de ser (Montibeller Filho, 2007).

Para tanto, quando se fala em consumo sustentável, existe todo um sistema envolvido, que deve ser efetivado de forma integrada para uma melhor promoção da sustentabilidade para que seja efetuada a longo prazo, para que seja garantido um meio ambiente preservado que possa ser perpetuado para as futuras gerações.

\section{Considerações Finais}

Percebeu-se através da pesquisa que o consumismo na contemporaneidade é fruto principalmente de diferentes funções que implicam em múltiplas referências como construção social, porém, nos padrões atuais, é insustentável, tanto na perspectiva ambiental quanto da construção de direitos e da cidadania.

Esse aumento no consumo, tem se transformando cada vez mais em tema de debates internacionais, que tratam de discutir as mudanças de postura do consumidor, apresentando como soluções modelos inovadores de negócios que articulam as relações econômicas, sociais e políticas para a incorporação dos valores sustentáveis no sistema vigente.

Diante disso, a repercussão pública sobre a questão ambiental tem motivado governos, organizações da sociedade civil, empresas e cidadãos a se reunirem e promoverem discussões da sustentabilidade, como um novo campo de ação, e forma de regulação, tendo como uma de suas exigências um modelo de produção e consumo sustentável. 
Research, Society and Development, v. 11, n. 2, e35811225739, 2022

(CC BY 4.0) | ISSN 2525-3409 | DOI: http://dx.doi.org/10.33448/rsd-v11i2.25739

Portanto é importante que aconteça uma reflexão sobre os problemas do desenvolvimento sustentável e se precisaria que fosse ampliado o enfoque de forma a dotar a discussão de uma visão mais ampla do que aquela restrita à economia de recursos ou reciclagem de resíduos.

Por fim, o consumo sustentável se apresenta como uma das possibilidades de tratamento da questão dos impactos gerados pelo consumismo. Ele envolve mudanças de atitude aliadas à necessidade de transformação do sistema de valores e atitudes dos cidadãos na esfera pública.

\section{Referências}

Agenda 21. (2001). Conferência das Nações unidas sobre meio ambiente e desenvolvimento. Curitiba: IPARDES. p. 260. https://periodicos.furg.br

Almeida, J. (2002). A problemática do desenvolvimento sustentável. In: Becker, D. F. Desenvolvimento sustentável: necessidade e/ou possibilidade? Santa Cruz do Sul: Edunisc. . p. 21-29. https://revistas.marilia.unesp.br

Brugger, P. (2004). Educação ou adestramento ambiental? 3. ed. Chapecó: Argos \Letras Contemporâneas, p. 199.

Cavalcante, C. A. G. et al. (2011). Desenvolvimento sustentável em tempos de consumismo. Revista de Casos e Consultoria, 2(3), e233, 1 jul. https://periodicos.ufrn.br

CPDS. (2000). Comissão de políticas de desenvolvimento sustentável e da agenda 21 nacional. Agenda 21 brasileira: bases para discussão. Brasília, DF: MMA: PNUD. https://antigo.mma.gov.br/responsabilidade-socioambiental/agenda-21/comissao-de-politica-de-desenvolvimento-sustentavel-e-da-agenda-21brasileira/itemlist/category/107-agenda-21.html

CMMAD. (1988). Comissão mundial sobre meio ambiente de desenvolvimento. Nosso Futuro Comum. Rio de Janeiro: Fundação Getúlio Vargas, 1988, p.4

Giddens, A. (2004). Sociologia. (4.ed.). Coimbra, Fundação Calouste Gulbenkian.

Guimarães, M. (2003). Sustentabilidade e educação ambiental In: Cunha, S. B.; Guerra, A. J. T. A questão ambiental: diferentes abordagens. Rio de Janeiro: Bertrand Brasil. p. 81-105.

Feldmann, F., \& Crespo, S. (2003). Consumo sustentável. Rio de Janeiro: v. 3.

Lowi, M. (2005). Ecologia e socialismo. Ed. Cortez.

Martins, A. R. P. (2006). Desenvolvimento Sustentável: uma análise das limitações do índice de desenvolvimento humano para refletir a sustentabilidade ambiental. Rio de Janeiro, 127 f. Dissertação (Mestrado) - Engenharia de Produção, Universidade Federal Fluminense, Niterói.

Milaré, É. (2007). Direito do ambiente: a gestão ambiental em foco. (5. ed.). Editora Revista dos Tribunais.

Montibeller-Filho, G. (2007). Crescimento econômico e sustentabilidade. Uberlândia, Sociedade \& Natureza. n. 19(1), p. 81-89.

Oliveira, J. C.C. (2012). Consumo sustentável. Veredas do Direito, Belo Horizonte, 9(17), 79-108 Janeiro.

Sachs, I. (2004). Desenvolvimento includente, sustentável, sustentado. Rio de Janeiro: Garamond.

Teixeira, E. B. (2005). Educação continuada corporativa: aprendizagem e desenvolvimento humano no setor metalmecânico. (Tese) Doutorado em Engenharia de Produção, UFSC, 2005. Florianópolis. 